\title{
Educación en la Araucanía. El mirar de los niños y niñas mapuche sobre sí mismos.
}

\author{
GUILLERMO WILLIAMSON C. ${ }^{1}$ \\ 1. Doctor en Educación. Director Departamento de Educación. Director Magister en Desarrollo Humano Local y Regional. \\ Universidad de la Frontera Chile.
}

Al pensar sobre que escribir pensé hacer algo centrado en cifras sobre infancia indígena o sobre Educación Intercultural Bilingüe (EIB), pero finalmente me decidí por presentar una reflexión sobre la educación asociada a la palabra dicha por los propios pichiqueche, niños y niñas mapuche. Hace unos años (2006) hicimos un breve estudio exploratorio sobre la infancia mapuche en La Araucanía* y aprovechamos alguna de su información, por otra parte recogemos nuestras experiencias y reflexiones sobre la EIB en la región.

Chile es un país que poco a poco va reconociendo a sus pueblos originarios y asumiéndose como un país multicultural con extensiones a la educación y a otros saberes y disciplinas del quehacer humano. La Ley Indígena $\left(\mathrm{N}^{\circ} 19.253\right.$, 1993) dio un primer impulso que se ha ido extendiendo hacia un complejo marco jurídico que abraza multiplicidad de áreas del desarrollo nacional, regional y local, estatal, civil e indígena: lo ambiental, lo político, lo jurídico, lo social, lo cultural, lo productivo y lo científico asociado a ello. En el área de la Salud en La Araucanía se han instalado en el nivel primario de atención los facilitadores interculturales (hablantes de mapudungun) que contribuyen a mejorar las comunicaciones con los beneficiarios del sistema y entre éstos reconociendo la diversidad de sentidos culturales atribuidos a las nociones de salud, medicina, enfermedad; machis empiezan a tener presencia en hospitales junto a médicos universitarios en diálogos interculturales contextualizados y significativos; se crean hospitales interculturales (v.gr. en Nueva Imperial); se capacita al personal en cultura indígena e interculturalidad; la formación universitaria del área de Salud empieza a integrar elementos culturales indígenas en diversas unidades de contenidos, en prácticas profesionales y programas de desarrollo. En educación a partir del año 1996 emerge en el Estado (Ministerio de Educación-MINEDUC y Corporación Nacional de Desarrollo Indígena-CONADI) la EIB a través de Programas de Educación Intercultural Bilingüe (PEIB), que desarrollan múltiples y variadas acciones en ámbitos curriculares, de investigación, diseño de materiales, pedagógicos, formación de educadores tradicionales, perfeccionamiento de profesores y funcionarios del estado, marcos regulatorios orientados a escuelas y procesos educativos rurales. Desde la Ley General de Educación-LGE (2006) se dictó el Decreto

\footnotetext{
* Proyecto Kelluwün: una nueva relación entre educación y comunidad local. (2008) Universidad de La Frontera (Proyecto Extensión Permanente 008/2008). Se hicieron talleres de conversación de niños y niñas mapuche sobre su infancia en escuelas de Nueva Imperial, Padre Las Casas, Puerto Saavedra, Teodoro Schmidt en la Región de La Araucanía.
}

Recibido el 7 de noviembre de 2012, aceptado para publicación el 27 de noviembre de 2012.

Correspondencia a:

Guillermo Williamson Castro

E-mail: guillermo.williamson@gmail.com 
Supremo del Ministerio de Educación N²80 (2009) que objetiva instalar progresivamente en el curriculum de las escuelas con una proporción superior al $20 \%$ de niños indígenas un sector de aprendizaje Lengua Indígena enseñado por educadores tradicionales escogidos por las propias comunidades. Hoy son varias cientos de escuelas rurales de la macrozona sur de Chile que cuentan con este sector y educadores tradicionales (kimeltuchefe) que la dictan**.

Esto refleja un fenómeno social, cultural y político que expresa una dinámica de revalorización de lo indígena -al menos en lo cultural y educacional- del país y de resistencia desde éstos en lo que dice respecto de sus lenguas y visiones de mundo. En ese contexto se ha ido reconociendo a la infancia no sólo el derecho a ser niño y niña, como lo asegura la Convención Internacional de los Derechos del Niño y la Adolescencia sino a ser niño y niña indígena, mapuche en la Araucanía, según lo indican los progresivos marcos legales nacionales e internacionales que aseguran derechos legales a los pueblos y a sus miembros, entre los cuales los niños, niñas, jóvenes. La Educación es uno de esos campos donde se ha ido avanzando, lenta y sostenidamente, en generar mayores espacios legales, curriculares y pedagógicos de expresión de cultura indígena y de interculturalidad. Pero, ¿qué es ser niño o niña mapuche? En el breve estudio exploratorio al que nos referimos hicimos algunos talleres con niños y niñas mapuche de varias identidades de La Araucanía de las cuales recogemos algunas ideas que nos permiten caracterizar a esas personas de las cuales los servicios de salud y educación deben preocuparse con prioridad y que constituyen indicativos de comprensión de la infancia indígena para aquellos (as) profesionales y académicos que se desempeñan con ellos.

\section{¿Qué es ser niño o niña mapuche?}

En relación a la identidad cultural de los niños y niñas que participaron de los talleres realizados en las escuelas, éstos identifican una serie de elementos que caracterizan el ser mapuche y que se pueden entender como elementos de su identidad. Al plantearles la pregunta: ¿qué es ser niño o niña a mapuche? Responden: "Tener apellido mapuche, tener herencia, por sangre, por el idioma, por la honradez, por el vestuario, la comida más seca". "Es tener sangre mapuche, vivir en el campo, sacrificado, resistente, trabajar la tierra". "Ser niño mapuche es hablar en mapuzugun, conocer de la cultura y no avergonzarse de ella. Participar en actividades propias de la cultura, conocer sus normas y vivirlas". "Un niño mapuche es el que tiene sus apellidos mapuche. También posee rasgos especiales, la cara, el pelo, que lo diferencian de otro no-mapuche".

Se trata de afirmaciones que identifican elementos valóricos, fisiológicos y culturales, idioma y territorio que son indicadores de aprecio y amor a su propia cultura, sin vergüenza. Afirman su autodefinición y pertenencia a un grupo humano distinto de otros, que tiene una cultura trasmitida por "herencia" donde la sangre, los apellidos, ciertas características físicas, las actividades que desarrollan (rurales), son componentes de su ser propio; en lo valórico, la honradez es una de las características del mapuche. Los elementos culturales apropiados, como comidas y vestuario y la participación en ceremonias religiosas $u$ otras, indican un reconocimiento de la existencia de normas propias de su cultura, las que hay que vivir y en consecuencia, respetar. El reconocimiento del idioma y del territorio se transforma en un llamado al uso de una lengua minorizada y amenazada de extinción, teniendo en cuenta que, según la UNESCO, cada 15 días desaparece una lengua en el mundo de las cerca de 7.000 que aún existen. Asimismo, la identificación de que la cara y el pelo son rasgos físicos definidos de identidad mapuche, reconociendo la sangre como elemento biológico de pertenencia a un determinado grupo humano -acompañada del amor propio, para no avergonzarse de ella-, es signo de marcada identidad, aunque deba ser más fortalecida en la escuela. Esta claridad la tienen los niños y

\footnotetext{
** Sólo en La Araucanía son 139 las escuelas focalizadas por el Programa Orígenes con proyecto EIB de Lengua Indígena (Fuente: MINEDUC, 2012).
} 
niñas de escuelas donde existe Educación Intercultural Bilingüe, por muy incipiente que ésta sea. Ésta, entonces, se transforma en un buen aporte en el ámbito de la retroalimentación cultural mapuche, pese a todo lo incipiente y precaria que ha sido en su aplicación.

\section{Niños(as) mapuche rurales y urbano(as), mapuche y no mapuche}

La conversación deriva a la identificación de algunas diferencias entre un niño mapuche y uno urbano, mapuche o no. Señalan que los niños mapuche "campesinos" se desenvuelven con más independencia, saben valerse mejor por sí mismos debido a la vida más sacrificada a la que están habituados, así como a la responsabilidad que deben asumir antes que el común de los niños. Por consiguiente, eso los conduce a una madurez más temprana. Ven, a los niños urbanos como más cómodos, porque dependen mucho de la colaboración de los padres y no tienen otras obligaciones que le signifiquen más sacrificio que levantarse temprano o exponerse al sol en el trabajo. "Los del campo son más maduros, más independientes para valerse por si mismos". "Los urbanos dependen más de que le hagan las cosas sus mamás u otras personas". "Los rurales son más alentados". Además, a ojos de los pichiqueche mapuche, los niños urbanos tienen más tiempo para jugar. Es interesante esta distinción de identidad entre niños mapuche (asociados a lo rural) y los de la ciudad (sean o no indígenas) que tiene que ver con su contexto de vida y su participación en los procesos económicos familiares y vida comunitaria en las cuales son más protagonistas.

Esta diferencia la reconocen también en los modos y espacios de la discriminación.

Los que están en las escuelas rurales mayoritariamente no perciben la discriminación racial ni de otra índole porque casi todos son mapuche y aquellos que no lo son no hacen la distinción, pues se sienten parte del contexto mapuche. Con la excepción de niñas del internado básico de Nueva Imperial, que no toleran la mofa o ridiculización que hacen sus compañeros de curso y profesor para amenizar la cla- se; niñas de Comio, Comuna de Padre Las Casas, señalan que no les gusta ir a clases, pues "las molestan porque sus padres sólo hablan en mapuzugun".

La discriminación la perciben los niños y niñas que ingresan a las escuelas urbanas: esta situación se traduce en un apocamiento, no sólo de su identidad mapuche, sino también de las personas por sus rasgos personales. Aquí el niño o niña se sitúa en un escenario de conflictos de identidad, en una lucha difícil y desigual de resistencia cultural donde muchos inexorablemente pierden la batalla y en adelante, tratarán de transformarse en incógnitos mapuche. Estos hechos generan sentimientos de pena e injusticia, que se reflejan en las afirmaciones realizadas por las niñas de un internado básico de Nueva Imperial: "Me da mucha pena cuando no me toman en cuenta". "Me siento mal porque me discriminan". "Nos sentimos mal, nos da pena".

Para ellos la discriminación racial en las escuelas rurales no es importante. Aunque niñas mapuche rurales internas de Nueva Imperial -y lo corrobora lo dicho por un niño de Isla Huapimanifiestan que en ocasiones sienten discriminación manifiesta, independiente de si son o no mapuche, en dos formas. La primera: que las segregan por pobreza, en el sentido de que sus compañeras y adultos las hacen sentirse mal por su condición de pobres. Estiman ellas que por esa vía se llega a la discriminación racial: como todas las mapuche se notan más pobres en su vestuario, o por falta de materiales, perciben que son miradas en menos. Sienten que en el común de las personas no-mapuche de las ciudades existen apreciaciones prejuiciosas, haciendo complementarios los conceptos de mapuche y pobreza: ser pobre es sinónimo de ser mapuche. La segunda razón, proviene de los adultos (frecuentemente los profesores) o algunos compañeros mapuche o no, por algunas características o rasgos personales como la lentitud para aprender, forma de caminar, el tamaño de la letra con que escriben, el estilo de modulación, las notas, por ser repitentes y por sus sobrenombres, caricaturizan a los alumnos. Los testimonios indican que se ríen de ellos en el curso incluso a costa de los defectos físicos de las alumnas. Las niñas denuncian que los 
profesores ejercen presión sicológica frente a reclamos de los alumnos, a quienes generalmente tratan de aislarlos. "Tenemos compañeros que se sienten discriminados por ser repitentes; los tratan de flojos, los aislan, hay sanciones negativas". "Son discriminados por ser mapuche, por su situación económica, Hay presión sicológica al reclamar sus derechos a ser respetados". "No me gusta que me digan india, porque me da mucha pena".

\section{Reflexiones finales}

Hemos seleccionado tres situaciones específicas que pueden ayudar a los profesionales $\mathrm{y}$ académicos que trabajan con niños y niñas indígenas a identificarlos en su ser: niño o niña son categorías generales, lo concreto es que tienen una identidad, la mapuche, que es concreta y culturalmente definida; una segunda característica que los define es su carácter urbano o rural que, según su modo de percibirse, son diferentes, sean o no mapuche; lo tercero es que esta diferencia se expresa en discriminación, principalmente en las ciudades, por pobreza, por su cultura, o ambas fusionadas, lo que marca su vida.

En cuanto a las proyecciones que hacen de sí mismos, todos conciben en que el estudio es la mejor alternativa para mejorar sus expectativas de vida. Pretenden terminar su enseñanza media, ojala en liceos técnico-profesionales y obtener un título. Pero hay claras diferencias con lo que piensan los que están internos y los que no, en muchos casos, no se proyectan más allá del término de la enseñanza media y se ven ejerciendo oficios como el de mecánico, secretaria, auxiliar de enfermería, chofer, panadero y labores relacionadas con la gastronomía. Los internos, en cambio, tienen proyecciones más ambiciosas y variadas: desde recibirse de técnico hasta trabajar para estudiar medicina, ingeniería, pedagogía, veterinaria, ser policía o diseñador de vestuarios. Dicen algunos adolescentes internos: "Sí, nos interesa estudiar, para conseguir lo que queremos". "Ser mecánico, militar, carabinero, profesora, doctora". "Medicina veterinaria, trabajar en el hospital, gastronomía, profesor de lenguaje, secretaria, carabinero, computación, diseñadora de ropa, gendarme". "Para retribuir a los papás, ayudarlos y que se sientan orgullosos".

La educación hoy está en crisis profunda, estas miradas de los niños y niñas son expresiones de miradas y voces que emergen desde el fondo de la crisis, donde se desarrollan experiencias que intentan responder, desde lo local y el quehacer pedagógico, a las legítimas y postergadas demandas de los pueblos indígenas y de sus niños y niñas respecto de su derecho a una identidad, lengua, cosmovisión propia e incluso a una educación intercultural que recoja dialécticamente el saber indígena, el de la sociedad global y el que surja del diálogo entre ambas. La Educación Intercultural Bilingüe es una de esas expresiones, no sin límites y dificultades, criticada pero al mismo tiempo conquistada, que se está llevando a cabo en las escuelas básicas rurales (en el Liceo y en las escuelas urbanas aún es un deseo). La educación y la salud si no escuchan las voces del saber indígena pierden la posibilidad de enriquecer sus fuentes de conocimiento para las comprensiones, emociones y prácticas académicas, sociales y educacionales que se desarrollan en los territorios; la actividad académica, política pública o social que no escucha ni permite participar o decidir a las familias y pichiqueche al final termina violando los derechos a ser niño y niña indígena educados, saludables, con identidad, felices. 